\title{
A abordagem da geomorfologia nos estudos de impacto ambiental para fins de licenciamento no Estado da Paraíba
}

\author{
The geomorphology approach in environmental impact studies for \\ purposes of licensing in the State of Paraíba
}

\author{
Henrique Elias Pessoa Gutierres', Jéssika de Oliveira Neles Rodrigues ", Camilla \\ Jerssica da Silva Santos "II, Valdeniza Delmondes Pereira IV
}

\section{RESUMO}

O aprimoramento metodológico e técnico do Estudo de Impacto Ambiental deve ser uma realidade a ser estudada e aprofundada para o aperfeiçoamento do licenciamento ambiental. O trabalho foi baseado numa pesquisa aplicada e descritiva sob o método documental. A pesquisa elaborou uma matriz de critérios adotada para a análise da abordagem geomorfológica do EIA de cada empreendimento, buscando orientar o trabalho e reduzir a subjetividade da análise. No recorte temporal de dez anos (2005-2014) foram analisados dezoito EIAs de diversos ramos de atividades. Verificaram-se acertos, mas também a existência de estudos deficientes em informações, dados equivocados, falta de clareza e objetividade, comprometendo a efetividade da abordagem geomorfológica nos Estudos de Impacto Ambiental.

\section{Palavras-chave: Abordagem geomorfológica; Estudo de Impacto Ambiental; Matriz de critérios}

\section{ABSTRACT}

The methodological and technical improvement of the Environmental Impact Study must be a reality to be studied and deepened in order to improve environmental licensing. The work was based on applied and descriptive research under the documentary method. The research elaborated a matrix of criteria adopted for the analysis of the geomorphological approach of the EIA of each enterprise, seeking to guide the work and reduce the subjectivity of the analysis. In the ten-year period (2005-2014), eighteen EIAs from different branches of activities were analyzed. There were successes, but also the existence of studies deficient in information, mistaken data, lack of clarity and objectivity, compromising the effectiveness of the geomorphological approach in Environmental Impact Studies.

Doutor em Geografia pela Universidade Federal de Pernambuco. Geógrafo do Laboratório de Planejamento e Gestão Ambiental (LAPLAG), Departamento de Geociências da Universidade Federal da Paraíba - Universidade Federal da Paraíba E-mail: hepg86@hotmail.com.ORCID: https://orcid.org/0000-0003-0220-3410

"Engenheira Ambiental e Mestra em Desenvolvimento e Meio

Ambiente (PRODEMA/Universidade Federal da Paraíba). E-mail: jessikaonr@hotmail.com ORCID https://orcid.org/0000-00034850-6361

II' Geógrafa, Mestra em Geografia (Universidade Federal da Paraíba) e Doutoranda do Programa de Pós-Graduação em Geografia (PPGG/Universidade Federal da Paraíba). E-mail: camilla.jerssica@hotmail.com . ORCID https://orcid.org/0000-0002-3029-8966

IV Geógrafa (Universidade Federal da Paraíba), Técnica em Meio Ambiente (Instituto Federal da Paraíba) e Técnica administrativa da UFPB. . E-mail: del_mondes@hotmail.com ORCID: https://orcid.org/0000-0001-7049-8260 
Keywords: Criteria matrix; Environmental Impact Study; Geomorphological approach

\section{INTRODUÇÃO}

A geomorfologia tem sua origem alicerçada em bases próprias, que proporcionaram, ao longo do tempo, um status de campo científico de grande relevância, especialmente nas geociências. Com o desenvolvimento e os avanços das discussões sobre o meio ambiente, diversos instrumentos de planejamento e de gestão ambiental foram sendo criados para as mais diversas finalidades. Tais instrumentos contemplam aspectos dos meios físico, biótico e antrópico, e a geomorfologia, que se encontra inserida no meio físico, mas estabelece relações interdisciplinares com os outros dois meios - "biótico" (VILES, 1988; CHESSMAN et al., 2006; MONTGOMERY, 2006; RENSCHLER et al., 2007; THOMS et al., 2018; VILES, 2019) e o "antrópico" (KONDOLF; PIEGAY, 2011; WILCOCK et al., 2013; ASHMORE, 2015; BRIERLEY E HOOKE, 2015), vem se constituindo em conhecimento fundamental e imprescindível no campo acadêmico e aplicado para as áreas do planejamento e da gestão ambiental. Guerra e Marçal (2006) destacam que a interface entre a Geomorfologia e o Planejamento é algo bastante instigante, pois o geomorfólogo pode fornecer técnicas de pesquisa e conhecimentos sobre a superfície terrestre, relacionadas às formas de relevo e aos processos associados.

Diversos instrumentos de planejamento e gestão ambiental (estudos de impacto ambiental, licenciamento ambiental, perícia ambiental, auditoria ambiental, zoneamento ambiental, plano de manejo de unidades de conservação, etc.) contemplam os conhecimentos geomorfológicos, sendo a menor ou maior demanda por esses conhecimentos resultante do objeto de estudo e/ou do ambiente sujeito à ocupação. É o caso do Estudo de Impacto Ambiental - com o seu respectivo Relatório de Impacto Ambiental (EIA/RIMA), exigidos para o licenciamento ambiental de obras e atividades de grande poder de degradação ambiental, conforme a exigência constitucional e as diretrizes previstas na legislação ambiental brasileira. 
Abordar o Estudo de Impacto Ambiental (EIA) é se reportar à Avaliação de Impacto Ambiental (AIA), enquanto instrumento de planejamento ambiental, que surgiu na National Environmental Policy Act (NEPA), a lei da política nacional do meio ambiente dos Estados Unidos, aprovada em 1969 e em vigor desde $1^{\circ}$ de janeiro de 1970. No Brasil, a AIA é um dos instrumentos da Política Nacional de Meio Ambiente, instituída pela Lei Federal $n^{\circ}$ 6.938/81, sendo caracterizada por um conjunto de procedimentos que visam assegurar, desde o início do processo, que se faça um exame sistemático dos impactos ambientais de uma ação proposta. Logo, entende-se que o EIA está inserido na AIA e o seu aprimoramento metodológico e técnico, tanto para sua elaboração, como para sua análise e implementação, deve ser uma realidade a ser estudada e aperfeiçoada, pois serão utilizados pelos tomadores de decisão para a aprovação ou rejeição do licenciamento ambiental de empreendimentos/atividades públicas ou privadas.

É inegável a importância da inserção da geomorfologia nos estudos ambientais para fins de licenciamento ambiental, contudo, o grande desafio é saber como esses estudos estão abordando e analisando os processos geomorfológicos e os riscos associados, que se fazem presentes nas fases de planejamento, de instalação e de operação dos empreendimentos. Sendo a geomorfologia um dos itens comuns do Termo de Referência (documento elaborado para nortear a elaboração do EIA), o presente artigo propõe analisar a abordagem geomorfológica nos EIAs encaminhados para o licenciamento ambiental de atividades/empreendimentos de diversas tipologias, no estado da Paraíba, entre os anos de 2005 e 2014. Logo, se propõe analisar os erros, os acertos e as deficiências na abordagem geomorfológica, permitindo o aperfeiçoamento na prática da elaboração, da análise e da implementação das recomendações desses estudos ambientais na gestão ambiental do empreendimento, compreendendo o campo da análise da qualidade dos EIAs (SIMPSON, 1996; LEE et al., 1999; BRASIL/MPF, 2004; AB'SABER, 2006; SANCHEZ, 2008; BITAR et al.., 2018). 
O artigo apresenta uma revisão da literatura pautada nos temas "Licenciamento ambiental e o Estudo de Impacto Ambiental", "A geomorfologia aplicada ao planejamento ambiental" e "A inserção da geomorfologia nos Estudos de Impacto Ambiental". O item seguinte aborda a metodologia do trabalho. Por fim, são apresentados e discutidos os resultados, finalizando com as considerações finais. 


\subsection{Licenciamento ambiental e o Estudo de Impacto Ambiental}

O licenciamento ambiental é um dos instrumentos elencados pela Política Nacional de Meio Ambiente (Lei Federal n 6.938/81). Para Struchel $(2016$, p.27) "é um procedimento, ou seja, é composto por atos encadeados visando a um fim, corolário da atuação estatal, no regular exercício do poder de polícia, o qual é exercido exclusivamente pelo Poder Executivo". No caso de obras ou atividades potencialmente causadoras de significativa degradação do meio ambiente, é obrigatória a elaboração do Estudo de Impacto Ambiental (EIA), objetivando subsidiar o licenciamento ambiental.

O EIA é um instrumento que permite avaliar as condições de planejamento para o uso e a ocupação de uma área, instalação e o desenvolvimento da atividade, associando ao ambiente que será objeto de ocupação, de forma a avaliar os impactos ambientais, estabelecendo medidas mitigadoras e programas ambientais de monitoramento, que permitirão concluir sobre a viabilidade daquele tipo de empreendimento numa determinada área. Para Christofoletti (1999), os ElAs são instrumentos que integram o conhecimento adquirido na análise dos sistemas ambientais com os objetivos das políticas de planejamento e manejo dos recursos, procurando coordenar a implantação da alternativa de melhor uso por meio de uma avaliação antecipativa.

Para tanto, a Resolução do Conselho Nacional de Meio Ambiente - CONAMA n ${ }^{\circ}$ 01/86 elenca as principais atividades técnicas na estruturação de um EIA: “Diagnóstico ambiental (meio físico, meio biológico e o meio socioeconômico)"; "Análise e identificação dos impactos ambientais"; "Definição das medidas mitigadoras para os impactos negativos"; e a "Elaboração do programa de acompanhamento dos impactos negativos e positivos". Diante da gama de conhecimentos exigidos e dos procedimentos a serem adotados, "a abordagem holística, integrativa, constitui a base 
6 | Título do artigo

fundamental para o planejamento e estudos de impactos" (CHRISTOFOLETTI, 1999, p.141). 


\subsection{A geomorfologia aplicada ao planejamento ambiental}

Para Santos (2004), os dados geomorfológicos permitem interpretar uma questão indispensável para o planejamento ambiental: a relação entre as configurações superficiais do terreno, a distribuição dos núcleos ou aglomerados humanos e dos usos do solo em função das limitações impostas pelo relevo. Portanto, o planejamento ambiental já vem sendo inserido na geomorfologia, como explica Panizza (1996), ao falar da geomorfologia ambiental. A "Geomorfologia Ambiental1", introduzida por Coates, é definida como "the practical use of geomorphology for the solution of problems where man wishes to transform or to use and change surficial processes" (COATES, 1971 APUD PANIZZA, 1996, p. 4).

Os resultados mais significativos desse ramo da geomorfologia, segundo Achkar e Dominguez (2011), aparecem no final da década de 1980, quando o nível aplicado da geomorfologia necessita gerar respostas às questões de natureza ambiental. Para Tricart (1977), a morfogênse ganha relevância ao contribuir para o ordenamento territorial e o planejamento, sendo a compreensão de tal dinâmica fundamental para a análise ambiental. O crescimento da inserção dessa vertente da geomorfologia é atestada socialmente, pois "environmental managers and the public have gradually recognized the relevance of geomorphology in environmental problem-solving, leading to greater numbers of geomorphologists interacting with public policy" (KNEUPFER AND PETERSEN, 2002 APUD DOWNS E BOOTH, 2011, p.84).

Santos (2004) entende que o planejamento acontece por meio de um processo contínuo de coleta, organização e análise sistematizada das informações, por meio de procedimentos e métodos, para chegar a decisões ou a escolhas acerca das melhores alternativas para o aproveitamento dos recursos disponíveis e para a ocupação de novas áreas. Planejar é estar a serviço do interesse público, por meio do ordenamento das atividades humanas. Logo, o planejamento ambiental baseia-se na 
integração e interação dos sistemas que compõem o ambiente, necessitando, portanto, de uma visão sistêmica e holística (SANTOS, 2004). A potencialidade aplicativa do conhecimento geomorfológico insere-se no diagnóstico das condições ambientais, contribuindo para orientar a alocação e o assentamento das atividades humanas (CHRISTOFOLETTI, 2007). Portanto, os estudos ou diagnósticos que sejam elaborados para o planejamento ambiental, tanto em escala regional, como municipal, ou urbano, necessitam da contribuição dos estudos geomorfológicos (ROSS, 2006). Sendo assim, pode-se conceber a matriz da Geomorfologia Ambiental por meio de uma abordagem integrada (sociedade e natureza), focando nos processos e formas advindos das influências antrópicas. Essa ação humana é responsável por gerar feições e formas de relevo em escala local. Tal área passou a se chamar de antropogeomorfologia, que destaca o papel desempenhado pelo homem enquanto fator de destaque na alteração das formas e dos processos geomorfológicos.

Hooke (1999) enfatiza que os geomorfólogos são cada vez mais solicitados a responder a perguntas sobre "o que", "como" e "por que" algo está acontecendo em um local específico e como isso pode ser resolvido. Para isso, os estudos geomorfológicos necessitam entender todo o sistema, a sua dinâmica de longo prazo e a observação da perspectiva espacial, por meio de uma abordagem muito mais holística para a análise de mudanças e a dinâmica dos sistemas, que vem sendo usada e defendida como a abordagem apropriada para a análise de problemas ambientais e a busca de soluções (NEWSON, 1992 apud HOOKE, 1999).

\subsection{A inserção da geomorfologia nos Estudos de Impacto Ambiental}

Diversos autores têm discutido a aplicação e uma maior inserção da geomorfologia nos EIAs (CHRISTOFOLETTI, 1999, 2007; ROSS, 1990, 2006; GUERRA E MARÇAL, 2006; DOWNS E BOOTH, 2011; PAES E VENTURI, 2011; SANCHEZ, 2013; MANTOVANI, 2015; GUERRA, 2018). Dentre as várias aplicações da abordagem 
geomorfológica nos EIAs, Ross (2006) considera que uma das preocupações é com relação aos impactos que o empreendimento trará ao relevo, induzindo impactos diretos (cortes, aterros, desmontes de morros, retilinização ou desvio de leitos fluviais) e/ou impactos indiretos (processos erosivos, movimentos de massa, inundações, assoreamentos), além de avaliar os efeitos ou as respostas que as características do relevo poderão exercer sobre o empreendimento. Logo, a geomorfologia ganha um papel de destaque no EIA, como uma das áreas do conhecimento que pode fornecer subsídios para evitar danos ambientais.

Sendo assim, a inserção do conhecimento geomorfológico no EIA pode ser pensada através de quatro perguntas elencadas por Sánchez (2013), voltadas para o planejamento dos EIAs: Quais as informações necessárias e para qual finalidade são utilizadas? Como serão coletadas essas informações? Onde serão coletadas? Durante quanto tempo, com qual frequência e em que épocas do ano serão coletadas? Portanto, metodologicamente, a abordagem da geomorfologia num EIA passa pelos questionamentos elencados, visto que os estudos geomorfológicos necessitam de critérios de espacialidade e temporalidade para muitas das investigações a serem desenvolvidas. Ao abordar os exemplos de estratégias para alguns levantamentos de dados na atividade de diagnóstico ambiental do EIA, Sánchez (2013) enquadra o "relevo" na coluna dos dados primários a serem obtidos. Para os estudos de impacto ambiental, a análise geomorfológica focaliza as questões relacionadas com a dinâmica processual e destaca os aspectos relacionados com a suscetibilidade e as reações das formas topográficas às mudanças, em face dos projetos previstos. Portanto, dentro do trabalho geomorfológico é necessária uma abordagem holística e integrada que incorpore as interações entre todos os componentes ambientais, incluindo a resposta humana (HOOKE, 1999; MEITZEN et al., 2013).

\section{METODOLOGIA}


Os dados a serem apresentados e discutidos foram levantados através da execução do Projeto de Pesquisa "A abordagem da geomorfologia nos EIAs/RIMAs no estado da Paraíba", desenvolvido no Departamento de Geociências da Universidade Federal da Paraíba (Figura 1). 


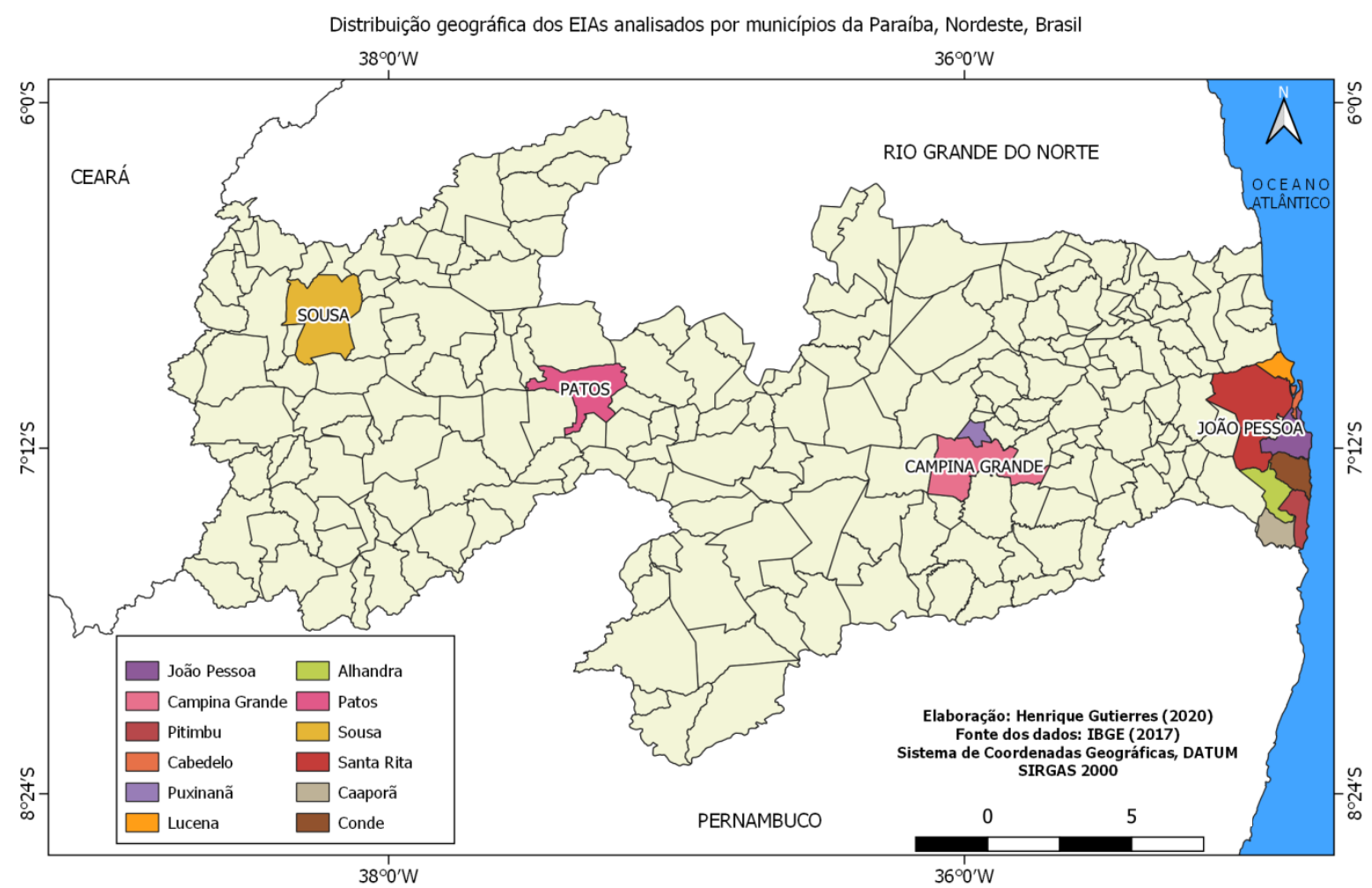

Foi utilizada a pesquisa exploratória resultante da revisão da literatura, da pesquisa documental e do preenchimento da matriz de análise técnico-documental, destinada à análise de conteúdo de um grupo amostral de 18 (dezoito) EIAs, protocolados e disponíveis no Centro de Documentação do órgão ambiental do estado da Paraíba (Superintendência de Administração do Meio Ambiente - SUDEMA), entre os anos de 2005 e 2014 (Quadro 1). Optou-se por um recorte temporal, diante de um maior caráter de representatividade analítica do estudo de casos, evitando subjetividade na escolha dos estudos (YIN, 2014). Tal análise é entendida como o processo intelectual de categorizar dados textuais qualitativos em entidades semelhantes, ou categorias conceituais, para identificar padrões consistentes e relações entre variáveis ou temas. Logo, permitindo, por meio da geração de dados e informações técnicas da realidade, analisar o uso dos conhecimentos geomorfológicos na elaboração dos ElAs. 
Sendo assim, a pesquisa foi desenvolvida através do levantamento e análise do material bibliográfico e documental; elaboração de um instrumento aplicado para a coleta e análise dos dados e conhecimentos obtidos na pesquisa documental; coleta, tratamento e sistematização de dados documentais; e a apresentação e discussão dos resultados obtidos. De acordo com Gil (2010), apesar da pesquisa documental se assemelhar à pesquisa bibliográfica, a primeira se utiliza de materiais que não foram objeto de um tratamento analítico ou reelaborados a partir do objeto da pesquisa, enquanto que a bibliográfica se utiliza das contribuições de diversos autores sobre um assunto específico.

O referencial teórico utilizado contemplou as publicações de autores que entendem O EIA como instrumento de planejamento ambiental (SANTOS, 2004; KIRCHHOFF, 2006; PAES, 2010; SÁNCHEZ, 2013; PEREIRA E GUTIERRES, 2018; GUTIERRES et al., 2018) e outros que abordam a importância dos conhecimentos geomorfológicos na elaboração desse estudo, como Cavallin et al. (1994), Panizza (1996), Ross (2006), Guerra e Marçal (2006), Christofoletti (2007), Morris e Therivel (2009), Downs e Booth (2011) e Gutierres et al. (2019), além do uso da legislação brasileira pertinente ao tema, especialmente das Resoluções do Conselho Nacional do Meio Ambiente - CONAMA nº 01/1986 e n²37/1997.

O levantamento foi realizado por meio de planilha eletrônica Excel, previamente estruturada em atividade de gabinete, resultando na obtenção de diversos dados, permitindo fazer uma breve caracterização dos empreendimentos/atividades (ano do EIA, empreendedor, atividade e municípios) dos EIAs analisados (Quadro 1).

Quadro 1 - Dados gerais dos EIAs analisados, no período de 2005-2014, no estado da Paraíba.

\begin{tabular}{|c|c|l|l|l|}
\hline EIA & Ano & \multicolumn{1}{|c|}{ Empreendedor } & \multicolumn{1}{|c|}{ Atividade } & Município \\
\hline EIA001 & 2005 & $\begin{array}{l}\text { ECO Villas Negócios } \\
\text { Imobiliários Ltda. }\end{array}$ & $\begin{array}{l}\text { Implantação de hotel } \\
\text { ecológico }\end{array}$ & Lucena \\
\hline EIA002 & 2006 & $\begin{array}{l}\text { Aqualuna Aquacultura } \\
\text { Ltda. }\end{array}$ & $\begin{array}{l}\text { Produção } \\
\text { comercialização de } \\
\text { camarão marinho }\end{array}$ & Lucena \\
\hline EIA003 & 2006 & Prefeitura Municipal de & $\begin{array}{l}\text { Implantação da Estação } \\
\text { João Pessoa }\end{array}$ \\
\hline
\end{tabular}




\begin{tabular}{|c|c|c|c|c|}
\hline & & João Pessoa & Ciência, Cultura e Arte & \\
\hline EIA004 & 2006 & $\begin{array}{l}\text { Departamento de } \\
\text { Estradas de Rodagem da } \\
\text { Paraíba (DER) }\end{array}$ & $\begin{array}{l}\text { Ligação viária entre as } \\
\text { avenidas Beira Rio, } \\
\text { Epitácio Pessoa e Rui } \\
\text { Carneiro }\end{array}$ & João Pessoa \\
\hline EIA005 & 2007 & $\begin{array}{lr}\text { Valero } & \text { Brasil } \\
\text { Investimento Imobiliário }\end{array}$ & $\begin{array}{l}\text { Complexo Turístico } \\
\text { Imobiliário Pitimbu Golf } \\
\text { Marine Resort }\end{array}$ & Pitimbu \\
\hline EIA006 & 2008 & $\begin{array}{l}\text { Borborema Energética } \\
\text { S.A }\end{array}$ & Termelétrica & Campina Grande \\
\hline EIA007 & 2008 & $\begin{array}{l}\text { Governo do estado da } \\
\text { Paraíba }\end{array}$ & Ponte Cabedelo-Lucena & Cabedelo/Lucena \\
\hline EIA008 & 2008 & $\begin{array}{l}\text { Governo do estado da } \\
\text { Paraíba }\end{array}$ & $\begin{array}{l}\text { Obra hídrica } \\
\text { aproveitamento } \\
\text { integrado das águas da } \\
\text { vertente litorânea }\end{array}$ & $\begin{array}{l}\text { Municípios da Mata } \\
\text { Paraibana e Agreste } \\
\text { Paraibano }\end{array}$ \\
\hline EIA009 & 2010 & $\begin{array}{l}\text { Prefeitura Municipal de } \\
\text { Puxinanã }\end{array}$ & Aterro Sanitário & Puxinanã \\
\hline EIA010 & 2010 & Foss e Consultores Ltda. & Condomínio Residencial & Alhandra \\
\hline EIA011 & 2010 & Elizabeth Cimentos Ltda. & Indústria cimenteira & Alhandra \\
\hline EIA012 & 2011 & $\begin{array}{l}\text { Lambari Gerador de } \\
\text { Energia S/A }\end{array}$ & Termelétrica & Campina Grande \\
\hline EIA013 & 2011 & $\begin{array}{l}\text { Companhia de Cimento } \\
\text { São Simão Ltda. }\end{array}$ & $\begin{array}{ll}\text { Mineração } & \text { (calcário, } \\
\text { argila e areia) } & \end{array}$ & Alhandra \\
\hline EIA014 & 2011 & Light Engenharia Ltda. & Aterro Sanitário & Patos \\
\hline EIA015 & 2012 & $\begin{array}{l}\text { Lord Negócios } \\
\text { Imobiliários Ltda }\end{array}$ & $\begin{array}{l}\text { Complexo Ecoturístico } \\
\text { Reserva Garaú }\end{array}$ & Conde \\
\hline EIA016 & 2012 & $\begin{array}{l}\text { Termelétrica } \\
\text { Termopower VI S.A }\end{array}$ & Termelétrica & Santa Rita \\
\hline EIA017 & 2012 & $\begin{array}{lr}\text { Companhia } & \text { de } \\
\text { Desenvolvimento } & \text { da } \\
\text { Paraíba } \quad-\quad \text { CINEP } \\
\text { (Governo do Estado) }\end{array}$ & Distrito Industrial & Caaporã \\
\hline EIA018 & 2014 & $\begin{array}{l}\text { Nova Sousa } \\
\text { Empreendimentos } \\
\text { Imobiliários }\end{array}$ & Loteamento Residencial & Sousa \\
\hline
\end{tabular}

Fonte: organização dos autores.

Posteriormente, iniciou-se a análise de coerência dos itens dos EIAs, especialmente aqueles passíveis de abordar a geomorfologia (Diagnóstico Ambiental, Análise dos Impactos Ambientais, Medidas Mitigadoras e Programas de Monitoramento), através de uma matriz de análise técnico-documental para a verificação de conteúdo e análise da abordagem geomorfológica dos EIAs (Quadro 2), a partir de um rigor técnico-científico, tomando como referência as atividades técnicas elencadas no art. $6^{\circ}$ da Resolução CONAMA $n^{\circ}$ 01/86, bem como os procedimentos técnicos da geomorfologia, experiência técnica dos autores do 
trabalho, como norteadores para elaboração dos quesitos. A elaboração da matriz buscou orientar o trabalho e reduzir a subjetividade da análise, além do seu uso ser um instrumento recomendado na análise da qualidade dos EIAs. Segundo Anifowose et al. (2016), a análise de conteúdo de amostras não probabilísticas de EIAs tem sustentado a pesquisa da AIA em todo o mundo.

A matriz é composta por 13 (treze) quesitos de análise, respondidos de forma objetiva ("Sim" e "Não"), além de um campo de "Comentários", utilizado durante a fase de coleta dos dados no Centro de Documentação da SUDEMA. A análise dos EIAs foi norteada por uma visão geossistêmica, de modo que a geomorfologia fosse pensada além das relações com as áreas do meio físico. Os resultados obtidos foram sistematizados e apresentados por meio de gráficos.

Quadro 2 - Matriz de análise técnico-documental para verificação de conteúdo e análise da abordagem geomorfológica dos EIAs, de acordo com o atendimento mínimo as atividades técnicas elencadas no art. 6 da Resolução CONAMA nº 01/86.

\section{QUESITOS DE ANÁLISE}

Sim Não Comentários

1.0 EIA declara expressamente e/ou demonstra por outros meios se houve levantamento de campo aplicado a geomorfologia?

2.A geomorfologia do local do empreendimento foi abordada no EIA?

3.A equipe fez uso de registros de fotografias terrestres/imagens de satélite, destacando a geomorfologia da área do empreendimento?

4.No EIA foi identificado o uso de instrumento (s) de campo para aquisição de dados que subsidiem a análise geomorfológica?

5.No EIA foi identificada a realização de análise (s) de laboratório para subsidiar a análise geomorfológica?

6.No EIA consta(m) mapa(s) geomorfológico(s) de detalhe que permitam a compreensão dos processos geomorfológicos na área?

7.No levantamento e/ou uso de dados secundários pertinentes à geomorfologia, constam referências de autores e/ou publicações técnicocientíficas da geomorfologia na "Bibliografia" do EIA?

8.Em relação ao levantamento de dados secundários, consta $(m)$ citação (ões) de publicações (trabalhos acadêmicos, artigos científicos, capítulos de livros, livros e outros) na "Bibliografia" do EIA, que tiveram como objeto de estudo áreas próximas ao local do empreendimento analisado pelo EIA ou sobre casos similares no passado em outras localidades? 


\begin{tabular}{|l|l|l|l|}
\hline $\begin{array}{l}\text { 9.O item "Análise dos impactos ambientais do projeto e de suas } \\
\text { alternativas" contemplou a geomorfologia? }\end{array}$ & & & \\
\hline $\begin{array}{l}\text { 10.Na atividade técnica de "Definição das Medidas Mitigadoras", houve a } \\
\text { proposição relacionada à área da Geomorfologia? }\end{array}$ & & & \\
\hline $\begin{array}{l}\text { 11.Foram propostos "Programas de Monitoramento" para os impactos e } \\
\text { medidas mitigadoras relacionados à área da Geomorfologia? }\end{array}$ & & \\
\hline $\begin{array}{l}\text { 12.Nos "Programas de Monitoramento", foram identificados indicadores } \\
\text { voltados para a geomorfologia? (exemplos: volume do material } \\
\text { erodido/quantidade de processos por área) }\end{array}$ & & & \\
\hline $\begin{array}{l}\text { 13.Nos "Programas de Monitoramento", foram indicados padrões de } \\
\text { gestão (metas, periodicidade, responsabilidades)? }\end{array}$ & & \\
\hline
\end{tabular}

Fonte: organização dos autores.

\section{RESULTADOS E DISCUSSÃO}

Do total de EIAs analisados, doze EIAs são da iniciativa privada e seis do setor público (governo estadual e prefeituras). A maioria dos estudos (72,2\%) se refere a empreendimentos/atividades localizados na mesorregião da Mata Paraibana, onde se encontra a capital do estado da Paraíba, João Pessoa, dentre outros municípios elencados no quadro 1 (Pitimbu, Alhandra, Cabedelo, Lucena, Santa Rita, Conde e Caaporã).

\subsection{Procedimentos e técnicas em geomorfologia para a elaboração do diagnóstico ambiental}

Uma das atividades técnicas mais importantes na elaboração de um EIA é a escolha e o uso de procedimentos e técnicas para o levantamento geomorfológico necessário à elaboração do diagnóstico ambiental. Ross e Fierz (2009) refletem sobre a importância do uso das técnicas de pesquisa em geomorfologia para uma correta interpretação e análise da área de estudo. Entendem que essa pesquisa percorre três etapas: trabalho de gabinete, trabalho de campo e trabalho de laboratório. Cooke e Doornkamp (1990) destacam técnicas e habilidades frequentemente adotadas pelos profissionais da geomorfologia voltadas para o gerenciamento ambiental, a exemplo do trabalho de campo, que permite uma maior confiabilidade no registro dos dados 
geomorfológicos apresentados no mapa, por exemplo. Para Sánchez (2008, p.163) os "trabalhos de campo frequentemente são um meio de coletar previamente dados não existentes e necessários para a análise dos impactos", já que os EIAs tratam de empreendimentos/atividades com uma localização geográfica específica.

A análise dos EIAs constatou que 63,8\% dos estudos demonstraram ter realizado "levantamento de campo" (Figura 02), enquanto que 36,1\% fizeram uso do registro fotográfico da área do empreendimento. Em alguns EIAs, inexistem fotos no item sobre a geomorfologia, ou, no caso do EIA05, que apresenta uma foto, mas, no item pedologia, apresenta diversas fotos que mostram claramente a geomorfologia do local. Em seu trabalho sobre a análise da abordagem geomorfológica em EIAs de projetos hidrelétricos, Aguiar (2015, p.96) destaca que os registros fotográficos “[...] são importantes na composição do diagnóstico ambiental, uma vez que se tornam atestados dos relatos presentes no texto, validando o conteúdo apresentado e fornecendo ao órgão licenciador maior segurança de análise". Logo, tais registros passam a constituir documentos de referência para as futuras fases do empreendimento, como meio de mostrar a situação atual da área, bem como um dos meios de prova da inexistência ou existência de determinada degradação ambiental, antes do início das obras, das formas de relevo presentes na área do empreendimento, dos processos geomorfológicos presentes ou com predisposição de ocorrer etc.

Ainda no levantamento de campo, destacam-se a observação e a interpretação da paisagem, que reflete uma série de eventos que não puderam ser presenciados. Contudo, a partir da observação é possível fazer interpretações das condições em que os eventos se deram, permitindo apontar suas causas e efeitos. Logo, consiste em interpretar e prever o comportamento do meio físico diante da intervenção prevista para uma determinada área, buscando adequar o projeto. No entanto, no trabalho de campo geomorfológico, em se tratando da atividade do diagnóstico ambiental, vale destacar a necessidade em se abordar a geomorfologia da área do empreendimento considerando a sazonalidade climática para o planejamento das 
atividades de campo, já que os levantamentos de dados primários realizados em períodos mais secos podem ocultar a magnitude e a frequência de alguns processos, como a erosão e os movimentos de massa, minimizando a dinâmica geomórfica da área analisada.

Por outro lado, em $66,7 \%$ dos EIAs não foi identificado o uso de instrumentos de campo para obtenção de dados que proporcionem uma melhor caracterização geomorfológica. Como exemplos desses usos, temos a medição das declividades das vertentes como recurso técnico para a análise geomorfológica ou a implementação de procedimentos técnicos para medição da erosão do solo - ravinas e voçorocas (pinos de erosão, as calhas de Gerlach, penetrômetro, drone etc.). Eventualmente, dependendo do tipo e da localização geográfica do projeto, podem ser aplicados procedimentos técnicos na área da geomorfologia costeira (uso do nível topográfico, mira e trenas para a obtenção dos dados que visem à elaboração do perfil praial, por exemplo).

Figura 2 - Procedimentos e técnicas adotados na análise geomorfológica dos EIAs analisados.

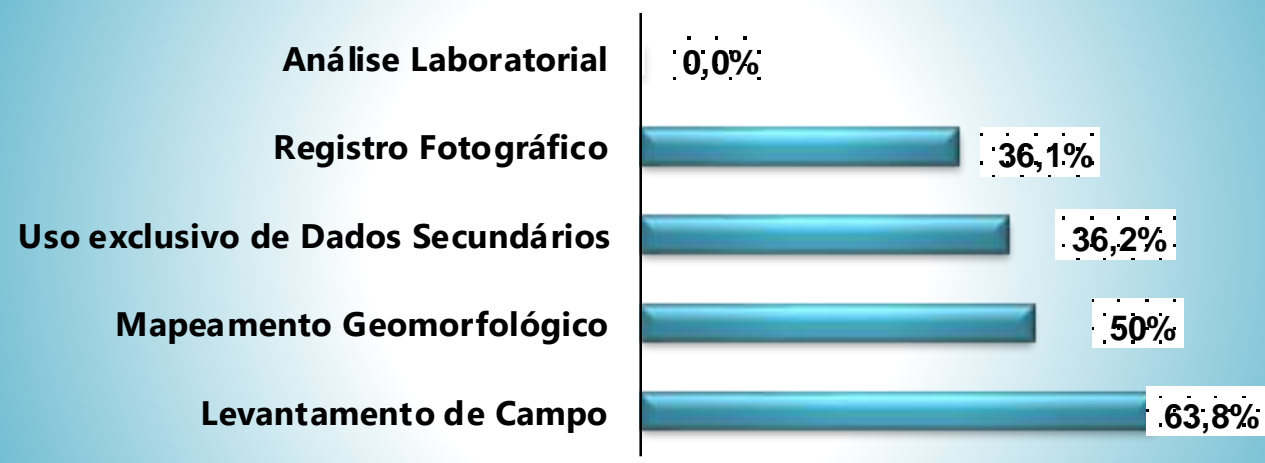

Fonte: Centro de Documentação da SUDEMA. Org.: Autores.

Já 36,2\% dos estudos fizeram uso, exclusivamente, de dados secundários, ou seja, aqueles que foram obtidos sem a execução de procedimentos de campo ou laboratório, restringindo-se ao uso de bibliografias. No entanto, poucos foram os EIAs que citaram publicações na "Bibliografia" do EIA, que tiveram como objeto de estudo áreas próximas ao local do empreendimento analisado. Vale salientar que o uso de dados secundários se constitui em um dos procedimentos de um EIA, conforme 
afirma Sánchez (2013, p.200), ao abordar que a "pesquisa bibliográfica e consulta a trabalhos similares são prováveis primeiros passos de uma equipe encarregada de planejar ou elaborar um estudo de impacto ambiental". Contudo, a equipe elaboradora não deve ficar restrita a tal fonte de dados. No tocante ao uso de bibliografias de autores da geomorfologia, os autores mais citados nos ElAs analisados foram: Aziz Ab'Saber, Jean Tricart, Antônio José Teixeira Guerra, Sandra Cunha e Jurandyr Ross.

Ainda em relação ao universo dos 36,2\% citados anteriormente, verificou-se que $23,8 \%$ não apresentavam uma caracterização geomorfológica mínima do local do empreendimento analisado. E com relação aos procedimentos de coleta de amostras no campo para "análise laboratorial", visando subsidiar a análise geomorfológica local, nenhum EIA adotou tal procedimento.

No que se refere ao mapeamento geomorfológico, este deveria ser um item obrigatório nos estudos ambientais para fins de licenciamento ambiental, pois os mapas permitem representar as formas do relevo e os respectivos processos de uma determinada área, sendo "essenciais para a representação da maioria das informações produzidas ou compiladas pelos estudos de base" (SÁNCHEZ, 2008, p.230). Identificou-se que $50 \%$ dos ElAs apresentaram mapas geomorfológicos que descrevem os processos geomorfológicos da área analisada. Para Ross e Fierz (2009, p.71), a cartografia geomorfológica está entre as técnicas mais utilizadas na área da geomorfologia, sendo aplicada para "mapear o que é observável e não o que se deduz da análise geomorfológica".

Assim, deve-se avaliar como a "área de estudo" e a "temporalidade dos estudos" podem ser voltados para a geomorfologia. Daí é indiscutível a importância da cartografia para o diagnóstico ambiental. Sobre isso, Sánchez (2013, p. 261) apresenta um quadro intitulado "Mapas temáticos empregados para diagnósticos ambientais". Na "Carta geomorfológica", o autor destaca que "[...] formas do relevo: formas estruturais, erosivas, de modelado fluvial, de litorâneo, cársticas, de antrópico, processos erosivos" devem ser contempladas nesse tipo de mapeamento. Assim, 
devendo representar os variados tamanhos das formas de relevo e a representação da morfometria, da morfogênese e da morfocronologia, vinculadas, de forma direta, aos tipos das formas (ROSS; FIERZ, 2009).

Foi possível verificar que, em alguns EIAs, os mapas estão sem a devida interpretação e visualização dos processos geomorfológicos, como no caso do "EIA08", cujo mapa geomorfológico apresenta uma escala satisfatória, porém, pela falta de nitidez da legenda, torna-se incompreensível a sua leitura. João (2002) demonstra a importância do uso correto da escala nos mapas de estudos ambientais, como forma de alertar, por meio da comparação de mapas com escalas diferentes e como isso resulta numa diferença considerável do detalhamento das informações a serem transmitidas. Portanto, a cartografia constitui um dos melhores caminhos para subsidiar uma análise geomorfológica. Um mapa geomorfológico com uma boa resolução cartográfica é um instrumento de leitura universal (KOHLER, 2001). A importância do Diagnóstico Ambiental no EIA é tanta, que o Ministério Público Federal, em sua publicação “Deficiências em estudos de impacto ambiental: síntese de uma experiência" (2004), afirma que "o EIA deve ser capaz de descrever e interpretar os recursos e processos que poderão ser afetados pela ação humana. Nesse contexto, o diagnóstico ambiental não é somente uma das etapas iniciais de um EIA: ele é, sobretudo, o primeiro elo de uma cadeia de procedimentos técnicos indissociáveis e interdependentes, que culminam com um prognóstico ambiental consistente e conclusivo". Logo, o diagnóstico ambiental é referência no cumprimento das próximas atividades técnicas no EIA ("análise dos impactos"; "definição das medidas mitigadoras"; "elaboração dos programas de acompanhamento e monitoramento", conforme determina a Resolução CONAMA n 01/86), sendo fundamental que seja bem estruturado para que seja efetivamente utilizado nas atividades técnicas posteriores.

\subsection{A aplicação dos conhecimentos geomorfológicos na avaliação dos impactos} ambientais 
Na atividade de avaliação dos impactos ambientais, a geomorfologia continua a ter a sua importância, conforme o entendimento de Ab'Saber (2006) de que a avaliação de impactos consiste em um processo complexo, que deve considerar todos os sistemas impactáveis que se sobrepõem e se entrecruzam. Segundo Guerra e Marçal (2006, p.70), a correta utilização dos conhecimentos geomorfológicos implica na diminuição da "probabilidade de ocorrerem danos ambientais, como movimentos de massa, erosão dos solos, erosão costeira, assoreamento, enchentes, etc., após a execução de grandes obras de engenharia, em especial quando o EIA/RIMA leva em conta esses riscos ambientais".

Existe uma gama de métodos de Avaliação de Impacto Ambiental (AIA) utilizados nos EIAs (Matriz de Leopold, Matriz de Correlação, Matriz de Interação, entre outros), porém, o enfoque dado na análise dos EIAs foi, apenas, em verificar se foram contemplados os impactos ambientais na área da geomorfologia, independente do método adotado em cada EIA. Os resultados obtidos permitiram identificar que $27,7 \%$ dos estudos não apresentaram nenhum impacto ambiental de natureza geomorfológica, enquanto que em $72,3 \%$ foram identificados impactos ambientais de cunho geomorfológico (Quadro 3). Dentre os impactos mais abordados, destacam-se (Figura 03): "erosão", "alteração morfológica", "assoreamento", “alteração do escoamento superficial", "deficiência de infiltração", "movimentos de massa", "compactação do solo" e "perda de solo". Cabe destacar que alguns estudos apresentaram mais de um impacto listado na figura 3.

Figura 3 - Identificação dos impactos ambientais relacionados à geomorfologia identificados

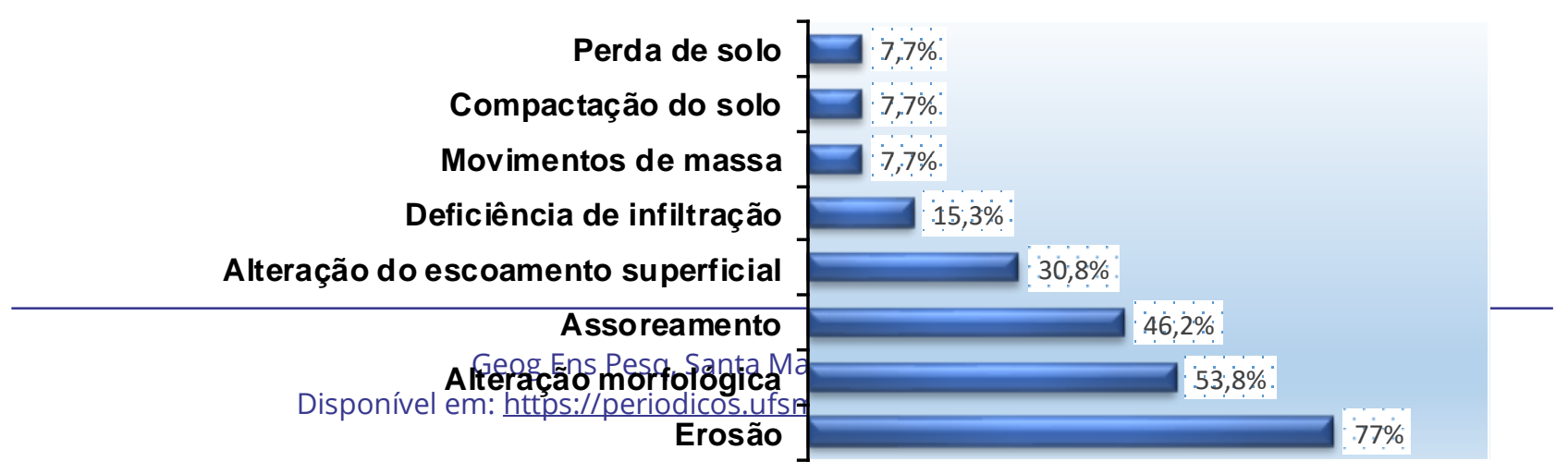


nos ElAs.

Fonte: Centro de Documentação da SUDEMA.

Org.: Autores.

Conforme se observa no gráfico, a "erosão" e a "alteração morfológica" foram os impactos mais citados nos estudos, tendo em vista que, dificilmente, uma obra será executada sem provocar alguma alteração, mesmo que de forma pontual e de curta duração. Em alguns casos, as erosões, principalmente as ravinas e voçorocas, promovem situações de risco geomorfológico, devido ao seu grande poder destrutivo, ameaçando habitações e equipamentos públicos, transformando-se no condicionante mais destacado para o assentamento das obras. Logo, a ocupação intensiva dos terrenos próximos às ocorrências erosivas aceleradas aumentam os riscos de acidentes.

A alteração morfológica foi o segundo impacto mais citado e que estabelece relação com as atividades de escavação, terraplanagem, dentre outras, presentes em praticamente qualquer EIA. É passível de ocorrer, pois toda obra de engenharia implica na transformação da paisagem, e, dependendo de onde seja instalado e do tipo do empreendimento, a morfologia sofrerá alguma modificação. Já em outras tipologias, como a mineração, essa alteração continua ao longo do período de operação da atividade. Sendo assim, 77\% dos estudos apresentaram impactos ambientais associados aos processos erosivos, que acabam se relacionando aos processos de assoreamento, que foram identificados em 46,2\% dos ElAs. Este percentual indica que o assoreamento não foi considerado como uma consequência dos processos erosivos nos outros 30,8\% dos estudos. Vale destacar que a produção de sedimentos provoca o assoreamento dos cursos de água e dos reservatórios, dentro das áreas urbanas e periurbanas, com a perda de capacidade dos reservatórios para abastecimento público, por exemplo.

Após o "assoreamento", a "alteração do escoamento superficial" é identificada em $30,8 \%$ dos EIAs analisados, constituindo mais um exemplo de impacto relacionado aos processos da dinâmica superficial. Em seguida, em 15,3\% dos estudos, foi citada a 
"deficiência de infiltração", que estabelece relação com os outros impactos ("compactação do solo" e "perda de solo"). Dessa forma, buscou-se verificar como foi a inserção e o tratamento dado ao conhecimento geomorfológico na avaliação dos impactos ambientais e na elaboração das medidas mitigadoras, bem como na concepção dos programas de monitoramento ambiental.

\subsection{0 uso dos conhecimentos geomorfológicos para a determinação das medidas mitigadoras e para a elaboração dos Programas Ambientais}

Após a identificação e a avaliação dos impactos ambientais, devem ser definidas as medidas mitigadoras e serem elaborados os programas ambientais, que permitam a minimização ou a eliminação dos impactos negativos e a potencialização dos impactos positivos.

Foi identificado que, em 77,8\% dos estudos, não houve a devida relação entre os impactos identificados na área da geomorfologia, o estabelecimento da(s) respectiva(s) medida(s) mitigadora(s) e a elaboração e indicação do(s) respectivo(s) programa(s) de monitoramento. Logo, alguns EIAs apresentaram “impacto-medida mitigadora-programa ambiental" de cunho geomorfológico, enquanto que outros abordaram apenas o "impacto-medida mitigadora" e, ainda sendo possível constatar a existência de EIAs sem nenhum impacto ambiental geomorfológico (quadro 3). Em cinco EIAs (001, 003, 007, 008 e 016) não houve qualquer indicação de impactos geomorfológicos. Enquanto que em oito estudos (001, 004, 006, 007, 008, 010, 012 e 016) não foi apresentada, no mínimo, uma medida mitigadora na área da geomorfologia. A indicação e descrição das medidas mitigadoras e compensatórias constituem condicionantes necessários para a análise da viabilidade de um empreendimento/atividade perante o licenciamento ambiental, já que nenhum projeto a ser licenciado terá ausência de impactos ambientais negativos. Logo, estes precisam ser mitigados ao máximo. 
Por outro lado, 14 EIAs não apresentaram programas de acompanhamento e monitoramento dos impactos e das medidas mitigadoras de cunho geomorfológico $(001,002,003,004,006,007,008,009,010,012,013,014,016$ e 017).

Sendo assim, os EIAs 001 (hotel), 007 (construção de ponte), 008 (obra hídrica) e 016 (termelétrica) foram os que não apresentaram nenhum impacto, nenhuma medida mitigadora e nenhum programa relacionado à geomorfologia. Portanto, “impacto/mitigação/monitoramento" devem estar relacionados, e a não existência dessa relação configura um programa de monitoramento falho e de pouca utilidade (SÁNCHEZ, 2013). Por outro lado, os EIAs 005, 011, 015 e 018 foram os que apresentaram as três atividades técnicas elencadas no quadro 3. Tratam-se de dois complexos turísticos, um loteamento residencial e uma indústria cimenteira. Todos estão convergindo com os impactos e as medidas definidas, já que estão restritos ao controle de processos erosivos, assoreamento e a recuperação de áreas degradadas. Enquanto que os programas indicados relacionaram-se aos "processos erosivos e assoreamento/sedimentação" e a "recuperação de áreas degradadas".

Quadro 3 - Impactos ambientais, medidas mitigadoras e programas de monitoramento de cunho geomorfológico.

\begin{tabular}{|c|c|c|c|}
\hline EIA & $\begin{array}{l}\text { IMPACTOS } \\
\text { AMBIENTAIS }\end{array}$ & MEDIDAS MITIGADORAS & $\begin{array}{c}\text { PROGRAMAS DE } \\
\text { ACOMPANHAMENTO E } \\
\text { MONITORAMENTO }\end{array}$ \\
\hline EIA001 & Nenhum & Nenhuma & Nenhum \\
\hline EIA002 & $\begin{array}{|lrr|}\text { Risco } & & \text { de } \\
\text { desestabilização } & \text { dos } \\
\text { terrenos } & \text { do } & \text { entorno; } \\
\text { podendo } & \text { provocar } \\
\text { erosão; } & \text { risco } & \text { de } \\
\text { erosão } & & \text { e } \\
\text { assoreamento. } & \end{array}$ & $\begin{array}{l}\text { Reflorestar áreas desnudas do } \\
\text { entorno do projeto. }\end{array}$ & Nenhum \\
\hline EIA003 & Nenhum & \begin{tabular}{lrr} 
Correção do & terreno para & que \\
materiais & excedentes & das \\
escavações & possam & ser \\
manejados; & minimizar & as \\
declividades e ressaltos, de modo \\
a contribuir para o controle das \\
\multicolumn{2}{l}{ águas pluviais. }
\end{tabular} & Nenhum \\
\hline
\end{tabular}




\begin{tabular}{|c|c|c|c|}
\hline EIA004 & $\begin{array}{l}\text { Escavação do solo, } \\
\text { desestabilização de } \\
\text { taludes, processos } \\
\text { erosivos, carreamento } \\
\text { de partículas sólidas, } \\
\text { assoreamento, } \\
\text { retirada da vegetação } \\
\text { nativa, extração de } \\
\text { argila na jazida de } \\
\text { empréstimo. }\end{array}$ & Nenhuma & Nenhum \\
\hline EIA005 & \begin{tabular}{ll}
\multicolumn{3}{l}{ Terraplanagem, } \\
erosão pluvial nas \\
subzonas, risco de \\
carreamento & de \\
sedimentos. Alteração \\
na paisagem, a partir \\
dos alicerces ou \\
escavações \\
necessárias para a \\
implantação do \\
empreendimento.
\end{tabular} & $\begin{array}{l}\text { Sistema de drenagem pluvial das } \\
\text { vias internas e públicas; } \\
\text { contemplar a captação e } \\
\text { infiltração das águas pluviais no } \\
\text { interior da área ou seu } \\
\text { encaminhamento direto para o } \\
\text { oceano, desde que o projeto anule } \\
\text { os efeitos de erosão e não cause } \\
\text { impacto com a paisagem praiana } \\
\text { e dispositivos de segurança para o } \\
\text { caso das chuvas excepcionais. }\end{array}$ & $\begin{array}{l}\text { Programa de Controle dos } \\
\text { processos erosivos } \\
\text { assoreamento } \\
\text { (Mapeamento das áreas } \\
\text { mais vulneráveis a erosão e } \\
\text { assoreamento; Realização } \\
\text { de um sistema de proteção } \\
\text { de taludes com plantio e } \\
\text { edificação do sistema de } \\
\text { drenagem; Seleção das } \\
\text { espécies vegetais indicadas } \\
\text { no plantio das áreas } \\
\text { degradadas e com maior } \\
\text { risco de erodibilidade). }\end{array}$ \\
\hline EIA006 & Processos erosivos & Nenhuma & Nenhum \\
\hline EIA007 & Nenhum & Nenhuma & Nenhum \\
\hline EIA008 & Nenhum & Nenhuma & Nenhum \\
\hline EIA009 & $\begin{array}{l}\text { Extração de argila na } \\
\text { fase de instalação }\end{array}$ & $\begin{array}{l}\text { Recuperar áreas degradadas - } \\
\text { plantando mudas de espécies } \\
\text { nativas }\end{array}$ & Nenhum \\
\hline EIA010 & \begin{tabular}{|lr} 
Processos rosivos; & erosão do solo; \\
erosão do & sedimentação dos \\
cursos dos rios; & perda \\
da capacidade de & \\
infiltração. & \\
\end{tabular} & Nenhuma & Nenhum \\
\hline EIA011 & $\begin{array}{l}\text { Alteração } \\
\text { morfológica; alteração } \\
\text { do escoamento } \\
\text { superficial. }\end{array}$ & $\begin{array}{l}\text { 1) Fazer o controle e diagnóstico } \\
\text { dos processos erosivos, visando } \\
\text { atenuar o processo de erosão; 2) } \\
\text { Proteger as margens da estrada } \\
\text { com plantio de vegetação de baixo } \\
\text { porte; 3) Ao se detectar sulcos } \\
\text { erosivos no leito das estradas, } \\
\text { proceder a recuperação com uso } \\
\text { de material de boa qualidade } \\
\text { geotécnica; 4) Conservar toda a } \\
\text { vegetação existente na AID do } \\
\text { projeto. }\end{array}$ & $\begin{array}{l}\text { Programa de Controle da } \\
\text { Erosão e Sedimentação. }\end{array}$ \\
\hline EIA012 & Processos erosivos & Nenhuma & Nenhum \\
\hline
\end{tabular}




\begin{tabular}{|c|c|c|c|}
\hline EIA013 & \begin{tabular}{|lr} 
1) & Alteração do relevo; \\
2) erosão; & 3) \\
escoamento & \\
superficial; & 4 ) \\
modificação & da \\
cobertura sedimentar.
\end{tabular} & $\begin{array}{l}\text { Controle dos processos erosivos; } \\
\text { conservação da vegetação. }\end{array}$ & Nenhum \\
\hline EIA014 & $\begin{array}{l}\text { Movimentação de } \\
\text { terra (escavação e } \\
\text { aterro); alteração do } \\
\text { escoamento } \\
\text { superficial; redução } \\
\text { da infiltração de } \\
\text { águas pluviais. }\end{array}$ & $\begin{array}{l}\text { Sistemas de controle a erosão } \\
\text { (desmatamento de forma } \\
\text { gradativa); instalação de sistemas } \\
\text { de drenagens das águas pluviais; } \\
\text { fazer o controle da terraplanagem; } \\
\text { sistemas de captação de águas } \\
\text { pluviais. }\end{array}$ & Nenhum \\
\hline EIA015 & $\begin{array}{lr}\text { Formação } & \text { de } \\
\text { processos } & \text { erosivos; } \\
\text { acirramento } & \text { de } \\
\text { processos } & \text { erosivos; } \\
\text { alterações } & \\
\text { morfológicas; } & \\
\text { instabilidade } & \text { da } \\
\text { dinâmica sedimentar. }\end{array}$ & $\begin{array}{l}\text { Instalação do canteiro de obras } \\
\text { em áreas cuja vegetação já se } \\
\text { encontra menos densa. }\end{array}$ & $\begin{array}{l}\text { Programas de recuperação } \\
\text { de áreas degradadas. }\end{array}$ \\
\hline EIA016 & Nenhum & Nenhuma & Nenhum \\
\hline EIA017 & $\begin{array}{ll}\text { Focos erosivos } & \mathrm{e} \\
\text { assoreamento } & \text { de } \\
\text { canais. } & \\
\end{array}$ & $\begin{array}{l}\text { 1) Implantação do projeto } \\
\text { paisagístico e das áreas verdes; } 2) \\
\text { Drenagem pluvial. }\end{array}$ & Nenhum \\
\hline
\end{tabular}

Fonte: organização dos autores - pesquisa documental.

Obs.: os textos foram transcritos integralmente como se encontram nos respectivos EIAs.

Conforme apresentado na figura 3, os impactos estão relacionados, quase que na sua totalidade, aos processos da dinâmica superficial. Tal cenário é pensado para a definição das medidas mitigadoras, já que as medidas propostas são, predominantemente, relacionadas à preservação/implantação da vegetação, a instalação de sistemas de drenagem, correção do terreno por meio da terraplanagem e a recuperação das áreas degradadas. Bitar et al. (2018, p.220) comentam que “medidas preventivas comuns em projetos de infraestrutura são as de controle de processos erosivos e de sedimentação em obras de terraplenagem". Bitar (1995) enfatiza a importância na caracterização dos processos do meio físico para fins de EIA:

A caracterização de processos do meio físico, em termos qualitativos ou quantitativos, deve ser tomada como um dos alicerces de um estudo de impacto. Sua importância é tão relevante quanto maior forem a clareza, a precisão e a eficiência que se desejem na previsão de alterações no ambiente, 
na avaliação de impactos e na formulação de medidas mitigadoras e de monitoramento (BITAR, 1995, p. 159).

Na elaboração de um EIA é fundamental explicitar o conceito de cada processo, registrando detalhes de seu mecanismo decorrente das particularidades do ambiente analisado, permitindo uma melhor orientação na sua análise e na avaliação das alterações (BITAR, 1995).

A definição dos impactos, das medidas e dos programas passa por uma correlação entre o ambiente a ser ocupado pelo empreendimento e a natureza da atividade desse empreendimento. E os EIAs precisam incorporar novas abordagens associadas ao campo da geomorfologia. Por exemplo, nos ElAs analisados não foi feita nenhuma referência ao termo "geodiversidade", enquanto conhecimento que também compreende os aspectos geomorfológicos e integra o patrimônio paisagístico de uma determinada área. Sendo a geodiversidade a variedade natural (diversidade) das feições geológicas (rochas, minerais, fósseis), geomorfológicas (paisagens, processos) e de solos (GRAY, 2004; MANSUR, 2018). Logo, identifica-se a necessidade dos futuros EIAs em incorporarem uma abordagem sobre a geodiversidade das áreas de influência do empreendimento.

Stevaux e Latrubesse (2017) destacam a necessidade em se gerar modelos voltados para o monitoramento ou a predição de impactos. E que a "nova geração de geomorfólogos terá a responsabilidade de reverter esse fato, do contrário continuará a haver avaliações pontuais (no espaço e no tempo) sobre os impactos gerados" (STEVAUX E LATRUBESSE, 2017, p.262). Para Mantovani (2015, p.15), a situação da geomorfologia nos EIAs revela que "[...] seu conteúdo mostra-se, por vezes, limitado a abordagens descritivas e caracterizações introdutórias dos estudos, em grande parte, orientadas por Termos de Referência genéricos elaborados pelos órgãos ambientais que conduzem o licenciamento ambiental". Logo, muitas vezes, as deficiências constatadas nos EIAs são decorrentes dos Termos de Referência mal elaborados, que se caracterizam por serem pouco exigentes e sem objetividade, fazendo com que a equipe elaboradora do estudo busque atender o que foi exigido, resultando, em 
muitos casos, na produção de um EIA de baixa qualidade e pouco efetivo na sua aplicação.

Por isso, a discussão sobre a abordagem da geomorfologia nesses estudos ambientais deve, também, perpassar por questões relacionadas à atuação profissional das equipes elaboradoras desses estudos. Sánchez (2013, p. 292) lembra que "[...] os profissionais das geociências vêm se preocupando em definir indicadores para medir e acompanhar os processos do meio físico modificados pela ação humana". Bitar et al. (2018, p.214) explicam que "os indicadores devem fornecer medidas da magnitude das situações atual e futura, para fins comparativos, devendo ser traduzidos por parâmetros quantitativos e/ou qualitativos". Logo, constituem uma forma objetiva para avaliar as alterações decorrentes do projeto a ser licenciado. Os autores apresentam exemplos de indicadores e parâmetros do meio físico que podem ser utilizados na abordagem dos processos do meio físico na avaliação de impactos ambientais de projetos. Dentre os processos elencados por Bitar et al. (2018) e que foram mais recorrentes, correlacionando com os processos presentes no quadro 3, destacam-se:

"Erosão hídrica": que tem como indicador as feições erosivas (sulcos, ravinas e voçorocas) e como parâmetros (comprimento, largura e profundidade - metros; área afetada - $\mathrm{m}^{2}$ ou ha; profundidade do N.A aflorante - em voçoroca).

"Deslizamento": que tem como indicadores (feições de massas em movimentação) e os parâmetros (comprimento e largura de trincas - cm, m; presença e altura de degraus - cm; inclinação - \%, graus; grau de saturação - \%; profundidade do N.A - m) e um outro indicador (feições de massas movimentadas) com a geometria, volume $\left(\mathrm{m}^{3}\right)$ e grau de saturação (\%) como parâmetros.

"Deposição de sedimentos ou partículas": que tem como indicadores (aporte de sedimentos) e os parâmetros (sedimentos em suspensão, mg/l ; vazão sólida/vazão líquida) e o indicador "dimensão do assoreamento", com o uso dos parâmetros (classificação do material - argila, silte, areia, detritos - e curva 
granulométrica \%; volume do depósito, $\mathrm{m}^{3}$; área ocupada no curso/corpo d'água, ha; área ocupada na zona de inundação, ha).

Logo, podemos considerar os exemplos citados como diretamente relacionados à geomorfologia de engenharia de vários projetos e, deve-se aprofundar a aplicação de outros indicadores de cunho geomorfológico nos diversos empreendimentos e atividades sujeitos ao Estudo de Impacto Ambiental.

Quanto à análise dos profissionais responsáveis pela estruturação dos 18 EIAs analisados, foi realizado o levantamento da composição das equipes elaboradoras. Em se tratando de uma pesquisa voltada para a geomorfologia, optou-se em focar a análise da atuação profissional nos profissionais das áreas de Geografia e da Geologia, considerando a origem da geomorfologia e a produção técnico-científica predominante por essas duas áreas científicas. Portanto, buscou-se verificar a presença do geógrafo e do geólogo nas equipes dos EIAs. A importância desses dois profissionais na elaboração de EIAs é demonstrada por Gutierres et al. (2018), que mostraram que o geólogo e geógrafo foram, respectivamente, o segundo e o terceiro profissionais mais presentes nas equipes elaboradoras de um universo de quarenta e três ElAs analisados. Os trabalhos de Paes (2010), Paes e Venturi (2011) e Gutierres et al. (2019) aprofundam os aspectos relacionados à atuação do geógrafo na elaboração dos EIAs/RIMAs.

Constatou-se a ausência de pelo menos um geógrafo ou um geólogo em dois EIAs. Em seis EIAs foi identificada a presença de, no mínimo, um geólogo e um geógrafo. Em outros cinco EIAs havia a presença de pelo menos um geólogo e em outros cinco estudos a presença de, no mínimo, um geógrafo. Portanto, em 33,3\% dos EIAs a equipe tinha a presença dos dois profissionais. No entanto, sabe-se que a presença de tais profissionais não garante que em todos os casos identificados a atuação aconteceu diretamente na área da geomorfologia, especialmente no caso dos geógrafos, já que alguns podem ter atuado em outras áreas do meio físico ou no estudo do meio socioeconômico, por exemplo. No entanto, permite mostrar que em quase $80 \%$ dos EIAs analisados, uma das profissões ou as duas estavam presentes na 
equipe técnica. Para Hooke (1988), os profissionais da geomorfologia devem atuar de forma conjunta com as pessoas responsáveis em tomar as decisões em nível governamental, de modo a influenciar as políticas públicas que estejam relacionadas ao meio físico. Bitar et al. (2018) vão além e destacam que a contribuição das geociências acontece nas diversas etapas da AIA, desde a etapa inicial, intermediária e as etapas pós-aprovação, quando da necessidade do "acompanhamento ambiental da fase de instalação e a gestão ambiental da fase de operação, bem como as atividades para a eventual desativação do empreendimento e a recuperação de áreas degradadas" (BITAR et al., 2018, p.214). 


\section{CONSIDERAÇÕES FINAIS}

A constatação de que parte dos estudos se pautou em dados secundários para a abordagem geomorfológica, demonstra que tal aspecto do diagnóstico ambiental foi colocado em segundo plano, como também expõe a deficiência do órgão ambiental licenciador em exigir um documento que avalie a realidade da área do empreendimento analisado. Por outro lado, considerando os EIAs que realizaram levantamento de campo, o baixo percentual daqueles que fizeram uso de registro fotográfico e do mapeamento geomorfológico, expõe um cenário de baixo nível de detalhamento da área do empreendimento. Por fim, a falta de análise laboratorial em todos os EIAs não corresponde com o impacto mais identificado que se relaciona à geomorfologia ("Erosão"), que tem na análise granulométrica um dos principais procedimentos para estimar a erodibilidade. Por outro lado, o grande percentual de EIAs que não estabeleceram a devida relação entre a avaliação dos impactos, o estabelecimento de medidas mitigadoras e os programas ambientais, demonstra o comprometimento do objetivo central do EIA, que é, a partir da identificação dos impactos, sejam positivos ou negativos, estabelecer as medidas e os programas que permitam minimizar ou eliminar os impactos negativos e potencializar os positivos.

A geomorfologia está totalmente inserida na concepção de planejamento ambiental, que trabalha, enfaticamente, sob a lógica da potencialidade e fragilidade do meio, definindo e espacializando ocupações, ações e atividades (SANTOS, 2004). Logo, foi possível verificar que uma parte dos estudos ambientais se mostraram deficientes em informações, dados equivocados, falta de clareza e objetividade. Todos esses problemas, no momento da elaboração do EIA, comprometem a transparência, o alcance e a efetividade desses estudos para que subsidiem o processo de licenciamento ambiental de empreendimentos públicos e privados. Com isso, os dados apresentados e discutidos demonstram que a geomorfologia poderia ter sido mais bem utilizada. Dessa forma, o EIA, que faz uma utilização correta dos 
conhecimentos geomorfológicos, oferecerá os meios para a solução e a prevenção de problemas ambientais ao invés de somente descrever o ambiente, garantindo uma tomada de decisão que possibilite gerar o menor número de impactos ambientais.

O EIA é um eficiente instrumento de planejamento e gestão ambiental, que necessita ser aperfeiçoado, principalmente pelos profissionais das equipes elaboradoras, empresas de consultoria ambiental e órgãos ambientais licenciadores. Logo, a questão a ser posta é o caminho para que a geomorfologia, inserida nos EIAs para fins de licenciamento ambiental, seja contemplada de forma criteriosa e com rigor técnico-científico, para que seja aplicada na elaboração, análise e implementação das ações de gestão. Para isso, se faz necessário o aprofundamento dos conhecimentos e o aprimoramento dos procedimentos e das técnicas de campo, laboratório e gabinete, inerentes à geomorfologia, que precisam estar presentes nesses estudos, bem como da análise criteriosa dos EIAs por parte dos órgãos ambientais licenciadores. Logo, os aspectos inerentes ao processo de elaboração de um estudo deste tipo vão além do que foi discutido, envolvendo também problemas técnicos e políticos implícitos no próprio processo de licenciamento ambiental no Brasil.

\section{REFERÊNCIAS}

AB'SABER, A. N. Bases conceptuais e papel do conhecimento na previsão de impactos. In: MÜLLER-PLANTENBERG, C.; AB'SABER, A. (Orgs.). Previsão de Impactos: o Estudo de Impacto Ambiental no Leste, Oeste e Sul. Experiências no Brasil, Rússia e Alemanha. São Paulo: Edusp, 2006. p. 27-50.

ACHKAR, M.; DOMÍNGUEZ, A.; PESCE, F. El pensamiento geográfico en Uruguay. Montevideo (Uruguai): LDSGAT, 2011.

AGUIAR, K. B. Análise da abordagem geomorfológica em Estudos de Impactos Ambientais (EIAs) de projetos hidrelétricos apresentados ao Instituto Brasileiro do Meio Ambiente e dos Recursos Naturais Renováveis (IBAMA) no período de 1993 a 2014. 2015. 145p. Dissertação (Mestrado em Geografia Física) - Universidade de São Paulo, São Paulo. 
ANIFOWOSE, B.; LAWLER, D.M.; VAN DER HORST, D.; CHAPMAN, L. A systematic quality assessment of Environmental Impact Statements in the oil and gas industry. Science of the Total Environment, v.572, p.570-585, 2016.

ASHMORE, P. Towards a sociogeomorphology of rivers. Geomorphology, v.251, p. 149-156, 2015

BITAR, O. Y. (Coord.). Curso de geologia aplicada ao meio ambiente. São Paulo: Associação Brasileira de Geologia de Engenharia (ABGE) e Instituto de Pesquisas Tecnológicas (IPT), 1995.

BITAR, O. Y.; ORTEGA, R. D.E.; GALLARDO, A. L. C. F. Avaliação de Impactos. In: OLIVEIRA, A. M. dos S.; MONTICELI, J. J. Geologia de Engenharia e Ambiental - volume 3. São Paulo: ABGE Associação Brasileira de Geologia de Engenharia e Ambiental, 2018. p.207-225.

BRASIL. MPF - MINISTÉRIO PÚBLICO FEDERAL. Deficiências em estudos de impacto ambiental: síntese de uma experiência. Brasília: Escola Superior do Ministério Público, 2004.

BRASIL. Resolução CONAMA nº 001, de 23 de janeiro de 1986. Disponível em: < http://www.mma.gov.br/port/conama/res/res86/res0186.html >. Acesso em: 03.06.2020

BRIERLEY, G. B.; HOOKE, J. Emerging geomorphic approaches to guide river management practices. Geomorphology, v.251, p. 1-5, 2015.

CAVALLIN, A.; MARCHETTI, M.; PANIZZA, M.; SOLDATI, M. The role of geomorphology in environmental impact assessment. Geomorphology, v.9, p. 143-153, 1994.

CHESSMAN, B. C.; FRYIRS, K.A.; BRIERLEY, G. J. Linking geomorphic character, behavior and condition to fluvial biodiversity: implications for river management. Aquatic Conservation: Marine and Freshwater Ecosystems, v.16, p. 267-288, 2006.

CHRISTOFOLETTI, A. Modelagem de Sistemas Ambientais. São Paulo: Edgar Blücher, 1999.

CHRISTOFOLETTI, A. Aplicabilidade do conhecimento geomorfológico nos projetos de planejamento. In: GUERRA, A. J. T.; CUNHA, S. B. Geomorfologia: uma atualização de bases e conceitos. Rio de Janeiro: Bertrand Brasil, 2007. p. 415-440.

COOKE, R.U.; DOORNKAMP, J.C. Geomorphology in Environmental Management: A New Introduction. 2. ed. Oxford (Inglaterra): Oxford University Press, 1990. 
DOWNS, P.W.; BOOTH, D.B. Geomorphology in Environmental Management. In: GREGORY, K.J.; GOUDIE, A. (eds.) Handbook of Geomorphology. London (Inglaterra): SAGE Publications Ltd., 2011. p.78-104.

GIL, A.C. Como elaborar projetos de Pesquisa. 5. ed. São Paulo: Editora Atlas, 2010.

GRAY, M. Geodiversity: valuing and conserving abiotic nature. 1. ed. Chichester (Inglaterra): John Wiley \& Sons, 2004.

GUERRA, A. J. T.; MARÇAL, M. dos S. Geomorfologia Ambiental. Rio de Janeiro: Bertrand do Brasil, 2006.

GUERRA, A.J.T. Geomorfologia e Planejamento ambiental - conceitos e aplicações. Revista de Geografia (Recife), Recife, v. 35, n. 4 (especial XII SINAGEO), p.269-287, 2018.

Gutierres, H. E. P.; SANTOS, C. J. S.; RODRIGUeS, J. O. N.; PereiRA, V. D. As equipes profissionais elaboradoras dos Estudos e Relatórios de Impacto Ambiental (EIAs/RIMAs): uma contribuição para o aprimoramento do licenciamento ambiental no Brasil. Revista Brasileira de Geografia Física, Recife, v.11, n. 5, p.1786-1802, 2018.

GUTIERRES, H. E. P.; SANTOS, C. J. S.; PEREIRA, V. D.; RODRIGUES, J. O. N. A atuação profissional do Geógrafo na elaboração dos Estudos e Relatórios de Impacto Ambiental (EIAs/RIMAs). Caderno de Geografia - Pontifícia Universidade Católica (PUC-MG), Belo Horizonte, v. 29, n. 59, p. 997-1028, 2019.

HOOKE, J. M. Geomorphology in Environmental Planning. Plymouth (Inglaterra): John Wiley and Sons Ltd., 1988.

HOOKE, J. M. Decades of change: contributions of geomorphology to fluvial and coastal engineering and management. Geomorphology, 31, p. 373-389, 1999.

JOÃO, E. How scale affects environmental impact assessment. Environmental Impact Assessment Review, Scotland, v.22, p. 289-310, 2002.

KIRCHHOFF, D. Capacity Building for EIA in Brazil: Preliminary Considerations and Problems to Be Overcome. Journal of Environmental Assessment Policy and Management, v.8, n.1, p.1-18, 2006.

KOHLER, H. C. A escala na análise geomorfológica. Revista Brasileira de Geomorfologia, v.2, n.1, pp. 21-23, 2001. 
KONDOLF, M.; PIEGAY, H. Geomorphology and Society. In: GREGORY, K. J., GOUDIE, A. G. (Eds.). The SAGE Handbook of Geomorphology. London (Inglaterra): SAGE Publications Ltd, 2011. p.105-120.

$L E E, N$. et al. Reviewing the quality of environmental statements and environmental appraisals. Manchester (Inglaterra): University of Manchester, 1999.

MANSUR, K. L. Patrimônio Geológico, Geoturismo e Geoconservação: uma abordagem da Geodiversidade pela vertente geológica. In: GUERRA, A. J. T.; JORGE, M. do C. O. Geoturismo, Geodiversidade, Geoconservação: Abordagens Geográficas e Geológicas. São Paulo: Oficina de Textos, 2018. p. 1-42.

MANTOVANI, J. da C. Geomorfologia aplicada aos Estudos de Impacto Ambiental de empreendimentos rodoviários: subsídios aos órgãos ambientais brasileiros. 2015. 203p. Dissertação (Mestrado em Geografia Física), Universidade de São Paulo, São Paulo.

MEITZEN, K. M.; DOYLE, M. W.; THOMS, M. C.; BURNS, C. E. Geomorphology within the interdisciplinary science of environmental flows. Geomorphology, 200, p. 143-154, 2013.

MONTGOMERY, D.R. Geomorphology and restoration ecology. Journal of Contemporary Water Research \& Education, 134, p.16-19, 2006.

MORRIS, P.; THERIVEL, R. Methods of environmental impact assessment. Londres (Inglaterra): Routledge, 2009.

PAES, H. G. Contribuições da Geografia ao licenciamento e ao Estudo de Impacto Ambiental. 2010. 148p. Dissertação (Mestrado em Geografia Física), Universidade de São Paulo, São Paulo.

PAES, H.G.; VENTURI, L.A.B. Profissão: geógrafo. In: VENTURI, L.A.B. (Org.). Geografia: práticas de campo, laboratório e sala de aula. São Paulo: editora Sarandi, 2011. p. 495-518.

PANIZZA, M. Environmental Geomorphology. Amsterdan (Holanda): Elsevier, 1996.

PEREIRA, V. D.; GUTIERRES, H. E. P. Análise da distribuição territorial dos empreendimentos com EIAs/RIMAs no Estado da Paraíba nos anos de 2003 a 2014. Revista de Geografia (UFPE), Recife, v.35, n.3, p.177-196, 2018.

RENSCHLER, C. S.; DOYLE, M. W.; THOMS, M. C. Geomorphology and ecosystems: Challenges and Keys for Success. Geomorphology, 89, p. 1-8, 2007. 
ROSS, J. L. S. Geomorfologia, ambiente e planejamento. São Paulo: Contexto, 1990.

ROSS, J. L. S. Geomorfologia Aplicada aos EIA`s-RIMA`s. In: GUERRA, A. J. T.; CUNHA, S. B. da (orgs.). Geomorfologia e Meio Ambiente. Rio de Janeiro: Bertrand Brasil, 2006. p. 291-336.

ROSS, J. L. S.; FIERZ, M. de S. M. Algumas técnicas de pesquisa em geomorfologia. In: VENTURI, Luis Antônio Bittar (Org.). Praticando geografia: técnicas de campo e laboratório. São Paulo: Oficina de Textos, 2009. p.69-84.

SÁNCHEZ, L. E. Avaliação de impacto ambiental: conceitos e métodos. São Paulo: Oficina de Textos, 2008.

SÁNCHEZ, L. E. Avaliação de impacto ambiental: conceitos e métodos. São Paulo: Oficina de Textos, 2013.

SANTOS, R. F. Planejamento Ambiental: Teoria e Prática. São Paulo: Oficina de Textos, 2004.

SIMPSON, B. Sustainability and environmental assessment: the Increasing Prominence of the Natural Environment in Development Decisions. Geography, v.81, n.3, p.205-216, 1996.

STEVAUX, J. C.; LATRUBESSE, E. M. Geomorfologia fluvial. São Paulo: Oficina de Textos, 2017. STRUCHEL, A.C. de O. Licenciamento ambiental municipal. São Paulo: Oficina de Textos, 2016.

THOMS, M. C.; MEITZEN, K. M.; JULIAN, J. P.; BUTLER, D.R. Bio-geomorphology and resilience thinking: Common ground and challenges. Geomorphology, v.305, p. 1-7, 2018.

TRICART, J. Ecodinâmica. Rio de Janeiro: SUPREN, 1977.

VILES, H. Biogeomorphology. Oxford (Inglaterra): Brasil Blackwell Ltd, 1988.

VILES, H. Biogeomorphology: Past, present and future. Geomorphology. In press, 2019.

WILCOCK, D.; BRIERLEY, D.; HOWITT, R. V. Ethnogeomorphology. Progress in Physical Geography: Earth and Environment, v.37, 5, p. 1-28, 2013.

YIN, R. K. Estudo de caso: planejamento e métodos. Porto Alegre: Bookman, 2014. 